\title{
Problematizing Affective Interaction Design
}

\author{
JONAS FRITSCH
}

\begin{abstract}
The notion of affect does take many forms, and you're right to begin by emphasizing that. To get anywhere with the concept, you have to retain the manyness of its forms. It's not something that can be reduced to one thing. Mainly because it's not a thing. It's an event, or a dimension of every event. What interests me in the concept is that if you approach it respecting its variety, you are presented with a field of questioning, a problematic field, where the customary divisions that questions about subjectivity, becoming, or the political are usually couched in, do not apply. (Brian Massumi 2009, "Of Microperception and Micropolitics").
\end{abstract}

This chapter is the result of a decade-long research engagement at the intersection between interaction design and affect studies. Through the prism of the interactive sound installation Voice Pump created during the timespan of the Affects, Interfaces, Events research project (see introduction), the aim of the chapter is to investigate the crafting of the installation as a form of transdisciplinary problematization of an emergent research agenda on affective interaction design. In Putting Problematization to the Test of Our Present (2019), Isabelle Stengers mobilizes the notion of problematization as it appears in the work of the late Michel Foucault - via the work of Gilles Deleuze and Etienne Souriau - to constitute a "keynote philosophical ethos of experimentation on ourselves in the present" (3). Stengers characterizes the present as "Catastrophic Times" (2013), demanding vigilance on an existential level towards crafting new "ontologies of ourselves" $(2019,4)$. To Stengers, we must allow ourselves to be "touched by" sensible events in the present that can be transformed into a call for action to change the current state of affairs. Changing here entails engaging with "reclaiming" and "ethopoetic" practices "aiming 
at the generation of ways of living, feeling and thinking that challenge social norms and manifest the transformative power of truth ... in order to experiment with the possibility of living in the capitalist ruins (2019, 13). Stengers emphasizes that a form of critique from the 'outside' is not an option; instead, problematization situates critique as a form of relaying practice "'at the frontiers', as the cultivation of a philosophical ethos, carrying out the work of thought under the experimental form of a historico-practical test imposed by our present, inseparable from the modes of problematization our present makes us capable of" $(2019,11)$.

Voice Pump is an air-based interface for attuning to the differential qualities of voices created by digital artist Mogens Jacobsen and me, the author. The interactive sound installation lets you 'pump up' voice recordings of around 20 diverse, both native and non-native, Danish speakers reading out loud the same page, an official "Learn Danish" textbook used

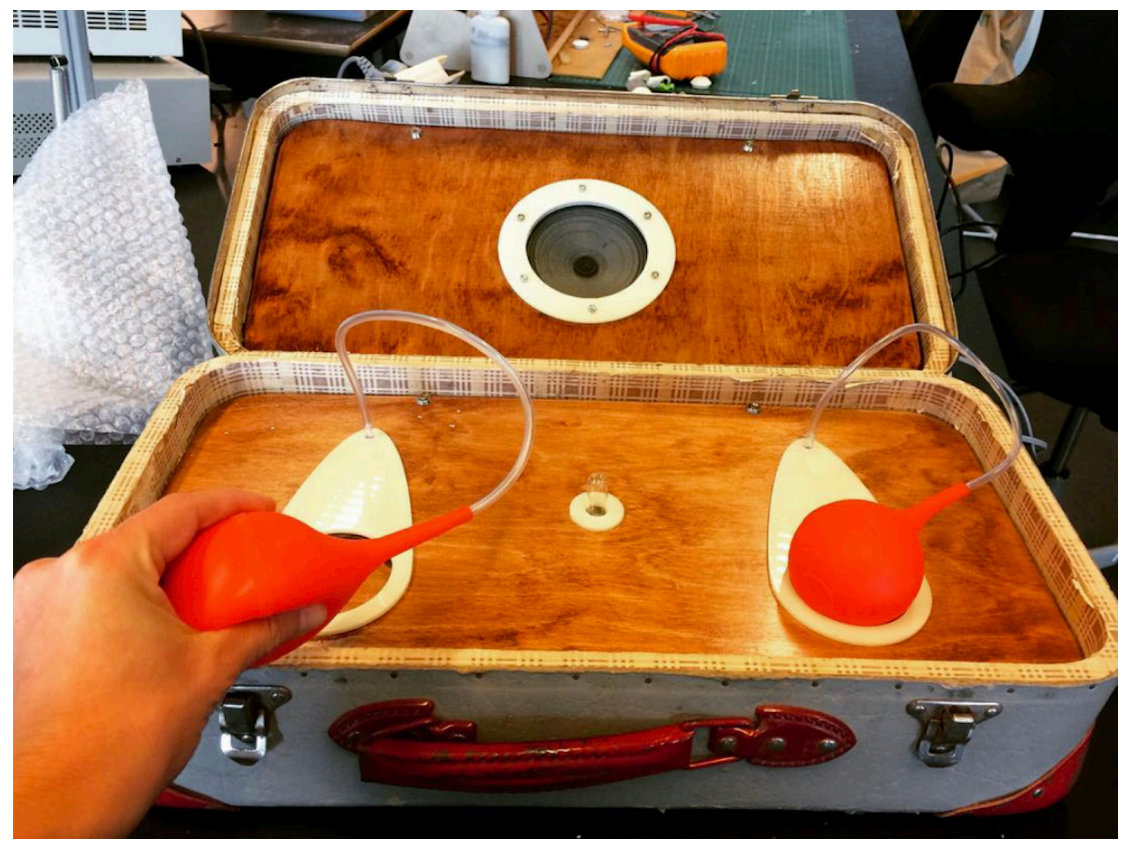

Figure 1. Physical form and pressure interaction with the Voice Pump. You need to maintain a steady airflow to make the voice speaker. Photo by Jonas Fritsch. 
in Danish classes offered by the municipality. Pressing the rubber pumps moves the recorded voices from low to normal to high pitch based on the airflow. You have to maintain a steady air pressure to hear the entire voice recording at a normal pitch, but you can also explore the low and high pitches to accentuate different affective qualities of the voices.

Voice Pump explores the potential in creating an interactive sound installation that lets people listen to and interact with actual voice recordings using rubber pumps as interaction devices. By using rubber pumps, the connection between controlled airflow and the spoken human voice is explored by using digital technologies. When interacting with the Voice Pump, the primary aim is not to engage directly with people's stories on a level of content. Rather, the aim is to engage people affectively through an experimental interface that allows them to attune through affective interactions to the paralinguistic qualities of voices, the qualities associated with these voices and the gestures involved in speaking a non-native language.

Problematizing the process leading to and the actual design of the Voice Pump will be retrospective since it attempts to revisit and relay findings from the project into a condensed format for others to engage with. At the same time, the project also points toward future explorations and cross-fertilizations across affect studies and interaction design, and beyond. In the chapter, I will show how at least two thematic trajectories might be distilled from this namely, 1) developing an affirmative ethics of technology exploration in affect studies fueled by digital design experiments and, 2) sketching out an ecological alter-politics of interaction design that directly engages with our present sociocultural, environmental, and mental crises on an ecological scale based on affect theoretical insights (Guattari 1989). The 'problematic fields' (see the Massumi opening quote) that have appeared out of the intertwinement of these trajectories has been fueled by an affect-driven inquiry that has both led to a personally motivated "ethos of experimentation" (Stengers 2019, 3) and the concurrent formulation of an emergent research agenda on affective interaction design as a conceptual and practice-based starting point for living out this ethos. In this respect, the chapter is also an exploration of the intersection between the personal and the collective, between living and (design) research. First, I will begin by sketching out what is meant by affective interaction design in the context of this chapter. 


\section{AFFECTIVE INTERACTION DESIGN AT A GLANCE}

Affective interaction design synthesizes trajectories from Human-Computer Interaction (HCI) (Picard 1997; Norman 2004; Lottridge et. al. 2011), interaction design (Sengers et al. 2002; Aboulafia \& Bannon 2004; Boehner et al. 2005; Höök 2008), and affect studies and philosophy (Spinoza 1678/1957; James 1912/2018; Whitehead 1929/1979; Deleuze 1970/1988; Stern 1985; Bennet 2001; Massumi 2002, 2009, 2015; Clough 2007; Gregg \& Seigworth 2010). ${ }^{1}$ Affective interaction design takes as a starting point a definition of affect as pre-personal intensity that influences our bodily, vital forces directly. Affect is directly related to a felt capacity to act and be acted upon through the increase or decrease of joy, sorrow or desire (Spinoza 1678; Massumi 2002). According to Spinoza, positive affects are those that make us feel alive and act in the world. Negative affects have the opposite effect, reducing our possible activity in the world and making this reduction felt. ${ }^{2}$ Affect is neither purely natural/ physiological, nor solely cultural. This also means that affect can neither be contained as the properties of a person, nor the properties of a system. Such a conceptual starting point for affect-driven inquiry thus challenges basic notions of interaction, interfaces, and interactivity in material, processual, relational and experiential terms (Fritsch 2009, 2011, 2018). Affective experience lies 'in-between' and thus brings together the natural and cultural in affective-felt tendencies that modulate the potential for action in a given situation. Starting from this middling field, affective experience entails looking into the very formation of experience; that which makes us experience and the forces that modulate this. Affect differs from emotion, which is understood as recognized affect; affect is pre-personal and non-conscious whereas emotion has individuated to a conscious form. Importantly, though, this does not entail that emotion should be disregarded as a concept in affective interaction design; rather, taking affect as a conceptual starting point for designing interfaces colors an entire spectrum of associated terms that must be entirely rethought in light of the modulatory power and processual working of affect. Some of the associated terms include emotion, feeling, mood, atmosphere, sensation, perception, sense, meaning, discourse, representation to name a few. These concepts require renewed consideration, continued conceptual exploration, and remain key to understanding how design works. They become increasingly important when inquiring into the use and adaptation of an interactive 
design over time, and how it changes affective attachments and relations in a longitudinal perspective where the affective formations temporarily stabilize into novel experiential fields. The emergent research agenda thus focuses on the resonance between affective interactions with concrete digital and interactive technologies (on a micro-level) that catalyze new affective attachments and relations (on a macro-level), and, perhaps most importantly, what happens in-between (meso-level).

If there is one thing we know from the recent years' studies within affect theory, you can never fully control affect; it is autonomous and unruly (e.g. Massumi 2002). Design, however, is often seen as an intentional act aimed at giving definite form to a controlled environment. However, it should be stressed that affective interaction design extends a line of thinking within HCI and design, arguing that the unfolding of interactions and relations can never be fully predetermined and that they emerge situationally; a 'designing for experience,' rather than 'designing experiences' (see e.g. McCarthy \& Wright 2004; Fritsch \& Iversen 2013).

The next section introduces the design of the air-based interactive sound installation the Voice Pump (2015-17). In many ways, this project has had a strong impact on the formulation of affective interaction design discussed here, since many of the basic ideas guiding the research agenda can be said to have materialized concurrently with the crafting of the design, either in direct relation to or in resonance with the project. However, the research agenda has also been shaped by some of the shortcomings and failures of the project to properly engage with the intended design situation it was supposed to contribute to. Voice Pump, then, will be used as a, "design to think with and through" (Frayling 1993; Zimmerman 2007), or a form of practice-based design research (Smith \& Dean 2009) exemplifying what happens when affect theoretical concerns enter directly into design processes and considering what questions arise from this exploration. Part of problematizing affective interaction design thus means to unravel what happens to affect theoretical concepts, concerns, and ideas when they move into design - the actual crafting of digital and interactive artifacts - and, of course, what happens in thinking and doing design driven by affect theoretical concepts. 


\section{DESIGNING THE VOICE PUMP}

The initial frame leading to the design of the Voice Pump, was my subproject within the project Affects, Interfaces, Events focused on the design of affectively engaging interfaces, especially looking into the use of digital and interactive sound. From this rather broad starting point, a range of brainstorming and sketching sessions were initiated to cultivate how a project within that frame might look. At the time of its initiation in 2015, the Danish (and European) so-called 'refugee crisis' was at its peak of intensity. For some time, I had been considering how to move my design research practice towards a more direct engagement with more pressing ecological and societal issues, and the refugee crisis became a "questioning situation" (Souriau 2015) that forced me to think about ways to move this personal ethos of experimentation into an exploratory design research practice. Receiving the Affects, Interfaces, Events grant also provided a unique opportunity to engage with this exploration. All these trajectories deeply influenced the collective ideation process, and very soon one of the criteria for the project emerged very strongly; we wanted the work to engage directly with the complicated affective politics surrounding the refugee crisis. This led to a focus on the potentiality of creating a design that would allow actual voices of refugees to be heard in the debate surrounding the crisis. One of our main reasons for focusing on different voices was that refugees were often referred to as a homogeneous group in everyday discussions and in the Danish media, and they were attributed with generic backgrounds and motives for seeking asylum in Denmark. Their motives were often perceived as "hostile" to Danish values or "Danishness," as defined by center-right political formations, such as an intentional and opportunistic exploitation of the Danish welfare system. When looking into the matter, it was clear that this generalization grossly hid the fact that the people coming to the country came from many different places, with their own individual stories - and voices. We therefore wanted to create an interactive installation that would make this differential felt, potentially creating a more nuanced perception of the diversity of the people behind the label 'refugees,' thereby making the differential 'heard.' We wanted to collect recordings of several refugee voices emphasizing their different tonalities and qualities by providing an affectively engaging way of interacting with - and relating to them. It also became an essential ethos of the project that it must be more than a 
'one-off' installation. To us, it represented an entry point into a continued engagement besides having a value in its own right. The design was a form of inquiry into this affectively saturated design situation (due to the political circumstances), as much as it was supposed to contribute to changing this situation.

The specific aim described above was already providing some direction, but it immediately opened a new range of questions that we also had to explore. We started out investigating voices, vocal qualities, and existing (interactive and non-interactive) works focusing on voices (e.g. see Figure 1). Simultaneously, we started investigating ways of entry into some of the temporary camps, which had been set up to accommodate the growing number of refugees, in order to find out what was going on and to find people who would participate in the project. We also went to a meeting at the Trampoline House, an NGO initiative facilitating encounters and activities between refugees, immigrants, and other people. We learned about the situation of the refugees in the camp, the challenges of being allowed into the camps, the many activities of the Trampoline House, and the necessity of building long-term relationships and not just entering mindlessly into other people's lives. This ethical commitment is also
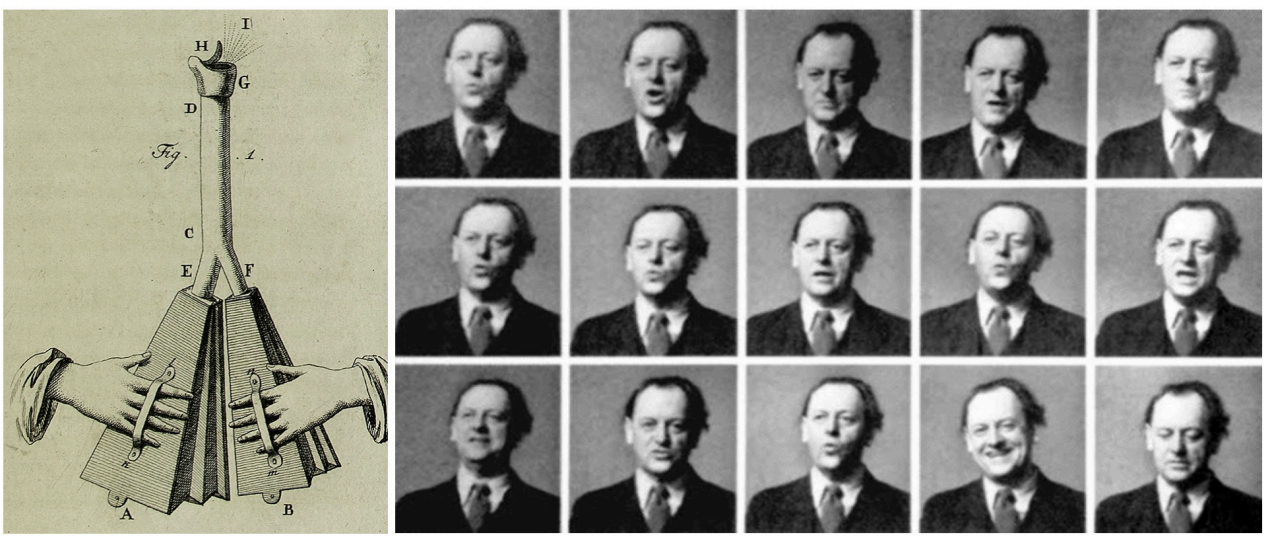

Figure 2. Sources of inspiration. Early speech synthesis using airflow controlled by bellows (left); illustration from Wolfgang Von Kempelen's "Mechanismus der menschlichen Sprache nebst der Beschreibung seiner sprechenden Maschine," 1791, SLUB Dresden, CC-BY-SA 4.O. Ursonate by Kurt Switters, 1932 (right). 
a central part of a range of other design disciplines, e.g., the participatory design tradition (e.g. Bødker et al. 1987; Munteanu et al. 2015). We kept in mind the importance of finding ways of entering other people's lives without attempting to 'get something out' without giving something back, and we continuously discussed what this entailed in practice.

At the same time, we were beginning to conduct experiments around how to create an affectively engaging form of interaction with the voices we wanted to collect. The tonality and coloring of individual voices are characterized by cuts in air distribution, and we wanted to play with this. Further, we wanted to explore the crafting of a physical interface that was "user-unfriendly" (Dunne 1999) and intensive as opposed to extensive (e.g. like waving a Nintendo Wii in the air). Our issue here was to put more demands on people's attention to make them interact more fully in exploring the design. This led us to use the feature of rubber pumps to blow air as an interaction device 'pumping up' voices in pitch. We reasoned that using air as a means of interaction would resonate with the way in which air, as respiration, regulates the physical production of voices. Further, we found that rubber pumps possessed intensive interaction modalities that were interesting to explore in the context of affective interaction design.

We decided to build a prototype that we could eventually share with refugee participants. This was a way to introduce them to our mode of engagement and particularly on our aim, and our ethical concerns, to not appropriate their voices. However, in testing the emerging technical infrastructure, we also wanted to start collecting some voices of non-native Danish people. Fortunately, we gained access to a group of non-Danish speakers in a Danish class. Originally, we had not given much consideration as to what the voices we would be collecting should say, since we thought of our primary design material as the qualities of a speaking voice rather than its utterances. So, for technical reasons we agreed to collect the same text being read by all the participants, which enabled us to better highlight differences in voices based on a comparison in articulation of the same words. Before visiting the class of newcomers learning Danish, we looked into the textbook material being used-a book entitled Lar Dansk (Learn Danish) - and picked out a dialogue which we thought would be interesting to record (see Figure 3). This dialogue was chosen in part because it did not make much sense; it was in fact quite nonsensical even though it was an essential part of the mandatory reading material for all immigrants and refugees coming to the country. They all, to this day, have to learn Danish 
and pass a language test to be able obtain citizenship. Therefore, we found this to be an interesting dilemma to enter into the design process. After listening to the recordings from four different people, from four different countries (three male, one female) we found it profoundly touching to listen to them trying to read in another language without being trained for it; the affective gestures of their effort to try to speak a foreign language was palpable and it colored the tonality of the recordings. These gestures were embedded in the sounds collected, and we decided to keep them as our key material along with the text:

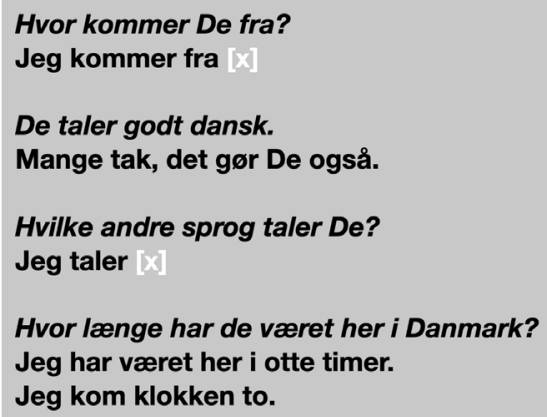

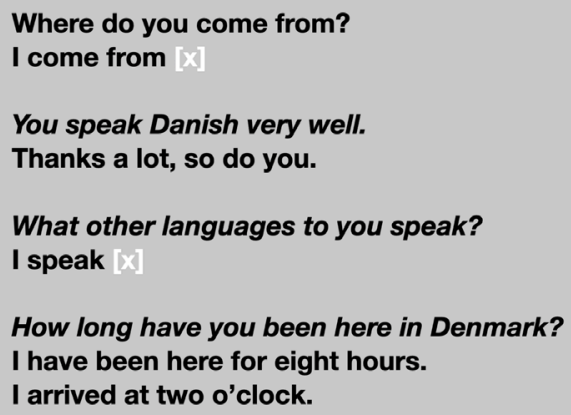

How long have you been here in Denmark? I have been here for eight hours. I arrived at two o'clock.

Figure 3. The text from the Learn Danish textbook that the participants would read out loud (left) and translated to English (right).

To facilitate experimentation of the mapping between interface and audio feedback, we decided to physically separate the interface and the audio playback. Thus, the final design of the Voice Pump consisted of two parts: a computer for sound-processing and a novel interface mechanism housed in a modified vintage suitcase (originally a carrying case for a 1962 East German vacuum cleaner). Communication between its parts is based on the standard OSC (Open Sound Control) protocol for networking electronic musical instruments and multimedia equipment.

The real-time audio processing on the computer (a Linux laptop or a Raspberry $\mathrm{Pi}$ ) is performed using the Minim audio library, which gave us the possibility to experiment with the mapping between the output of the user interface-i.e. air pressure - and audio parameters such as pitch, gain, echo, low pass filtering, and thresholds for starting and stopping 
the playback. The tactile interface consists of two rubber pumps each connected to air-pressure sensors (piezoresistive transducers). These two sensors interface to an Arduino microprocessor that embeds the air-pressure values in OSC-messages and communicates with the computer via an Ethernet board. During an interactive session, it is possible to play two separate audio-tracks tied to each of the two rubber pumps. Each of them controls the speed and pitch of a prerecorded audio-track. If both tracks get in sync (within a tolerance of $600 \mathrm{~ms}$ ), the system replaces the current set of voices with a new set of voices. ${ }^{3}$

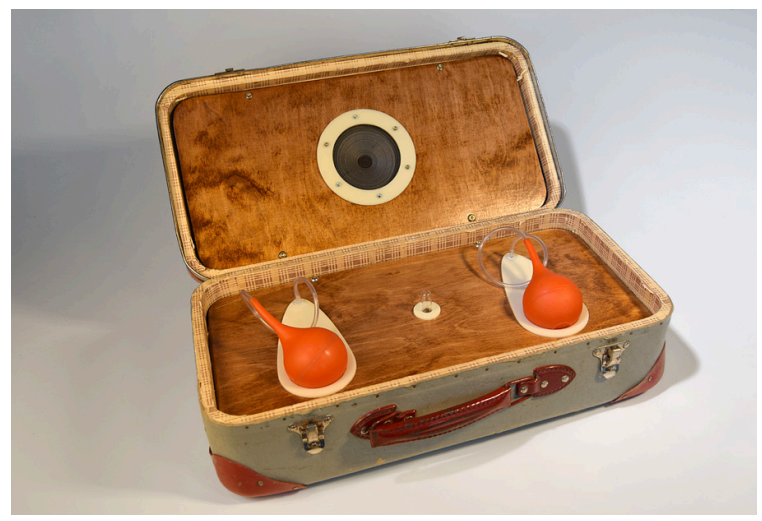

Figure 4. The Voice Pump (top), photo by Ben Cahill, ITU and its technical infrastructure (bottom), model made by Mogens Jacobsen.

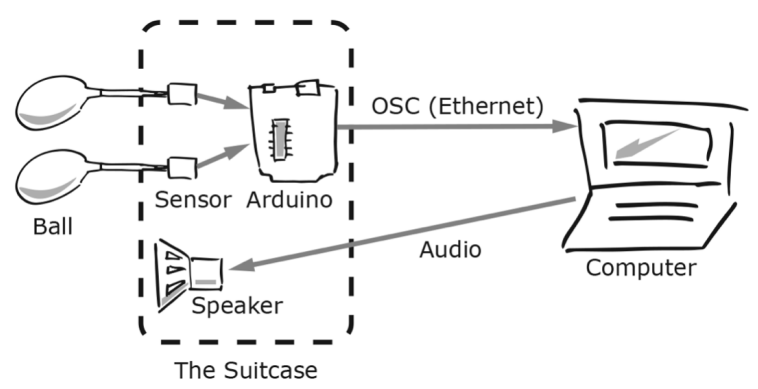


When trying out the interaction with the voices and the way in which they were modulated in pitch, we found that it was almost impossible to distinguish between gender and nationality; the voices would blur and intermingle until you would actually succeed in providing an appropriate amount of air into the pumps which could be achieved by gently squeezing the pumps continuously. Too little air, and the voices would sound like guttural utterances and eventually stop; too much air, and they would be squeaking.

All this resulted in a running prototype developed over the course of two years. It took its shape from hands-on experimentation and crafting, from conceptual explorations and from contextual/situational factors. We had arrived at a point in time, where we would be able to, as we had previously envisioned, bring the prototype into the refugee camps to start recording voices. But this never happened. One of the main reasons was that it had become almost impossible to gain access to the refugee camps that had been shut down for, among other things, political reasons. Another reason was that a range of activist groups were already engaged in fighting for the rights of the refugees, and we were, quite frankly and as will be discussed later in the text, not sure how the project would fit into this situation. All these considerations led to a shift in the project, where we turned our focus towards exploring more broadly the affective qualities of voices from both Danish and non-native Danish speakers. We did our biggest recording at a public event entitled Kulturnat (Culture Night) in 2018 at the IT University of Copenhagen, where we collected more than 18 different voices that ended up being the main vocal component in the final version of the installation.

\section{AFFECTIVE ENCOUNTERS AND NON-ENCOUNTERS WITH- AND THROUGH TECHNOLOGY}

During and after the design process leading to the creation of the Voice Pump, we presented the prototype at different venues and received valuable feedback from colleagues and other users at numerous academic and public events. ${ }^{4}$ These encounters were documented through photos, on video, in notetaking and in interviews. Some interactions had a more informal character, others a more performative one. One such important encounter was at an internal workshop in the Affects, Interfaces, Events project held at the IT University of Copenhagen in March 2017. 


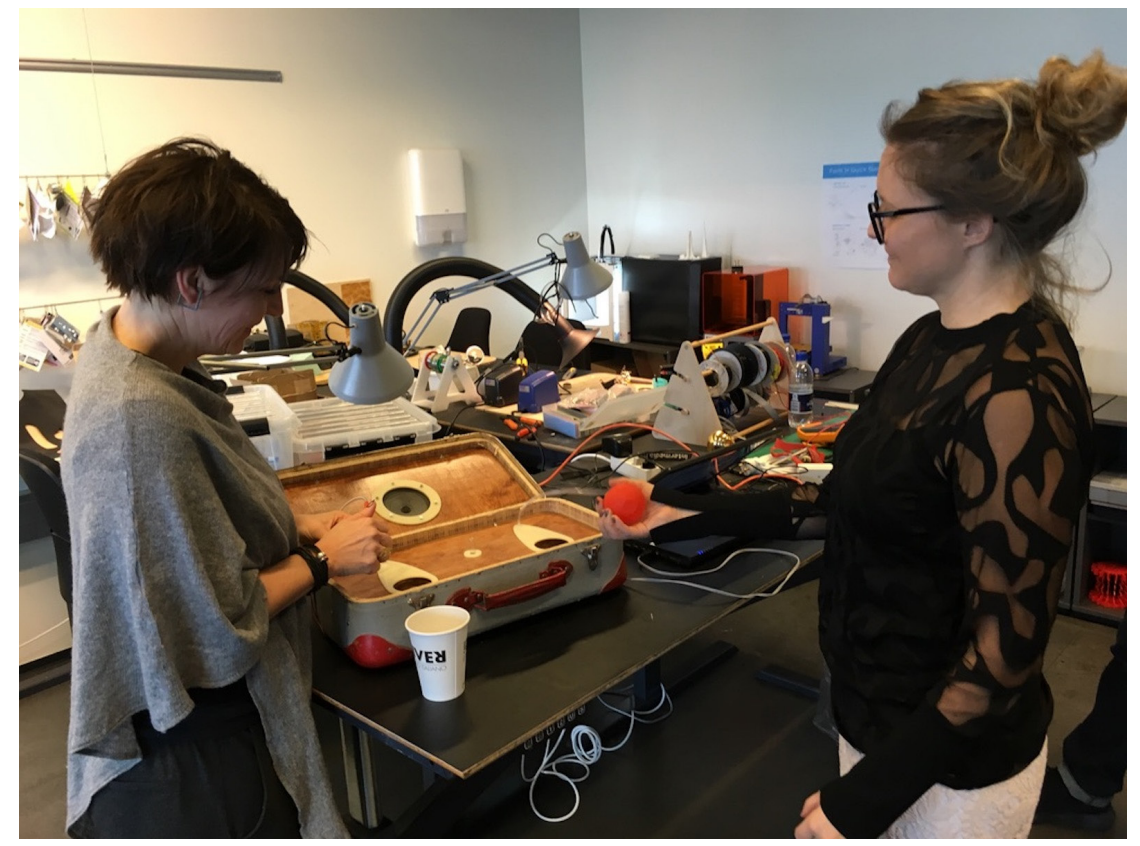

Figure 5. The Voice Pump at the internal AIE workshop at ITU. Photo by Jonas Fritsch.

In the workshop, we had been discussing the framing of the Voice Pump project based on a presentation of the background and thoughts going into the affect-theoretical-and societal framing. After this, we went to the lab where the prototype was placed, and people had a chance to test it out. This hands-on exploration had a profound impact on the way in which the workshop participants could both relate to the conceptual underpinnings and the overall project. People were frustrated that they did not succeed in making the voices speak, since they wanted to hear what they had to say. At the time, the framing of the project was around the refugee voices and this framing, combined with the impossibility to actually make the voices speak, provoked negative affect among a range of the workshop participants; it was their lack of interactional capabilities that kept the voices silent. Some mentioned that the urge to make the voices heard was intimately connected to the knowledge that these were voices of refugees, voices that were normally repressed. In this context the intensive 
interaction and user-unfriendliness resulted in a frustration which was palpable and colored the affective tonality of the experience. This led to renewed discussions around who gets to talk and who is silenced in the public debate, about the use of digital technologies to create unpleasant experiences, and how to engage in affectively saturated design situations dealing with politically controversial issues. Fueled by the actual hands-on experience of trying the installation, the parameters for engaging in the discussion shifted.

There were also less uncomfortable experiences of interacting with the installation. In September 2017, we presented the Voice Pump as part of a discussion focusing on sound in interaction design at a tech- orientated conference called SUMMIT. Here, the voices had been changed from refugees to non-native Danish speaking voices, which most likely also played a large part in people's more comfortable experience. The people interacting with the voices still wanted to make the voices speak, but the interaction was much more playful.

From this insight emerged a growing interest in exploring voicebased and conversational interfaces as affective design material. Voices immediately and deeply connect to feelings of identity, community, and intimacy, and they can be explored as a multifaceted design material for creating affectively engaging interactions. Synthetic Voice Assistants such as Apple's Siri, Amazon's Alexa, the Google Assistant, or Samsung's Bixby are increasingly entangled with our everyday lives, and this fundamentally changes how we conceive of listening, speaking, and 'giving voice' to people and things. This raises a range of aesthetic, ethical, and political questions that ask to be scrutinized further from an affect-oriented perspective. We are currently exploring this line of inquiry in a range of design projects at the Affective Interactions \& Relations (AIR) Lab at ITU, ${ }^{5}$ one of which is about exploring alternative synthetic voice design towards increased vocal diversity.

Voice Pump has been exhibited at quite diverse venues which results in sometimes conflicting reactions to its setup. At the Distributing the Insensible workshop, for example, held in Montréal in 2016 as part of the Immediations research project, the installation was explored by a diverse group of international artists, philosophers, and researchers. It was one installation among a number of performances, activities, readings, and much more. Being an international crowd, the attunement to the voices was primarily 

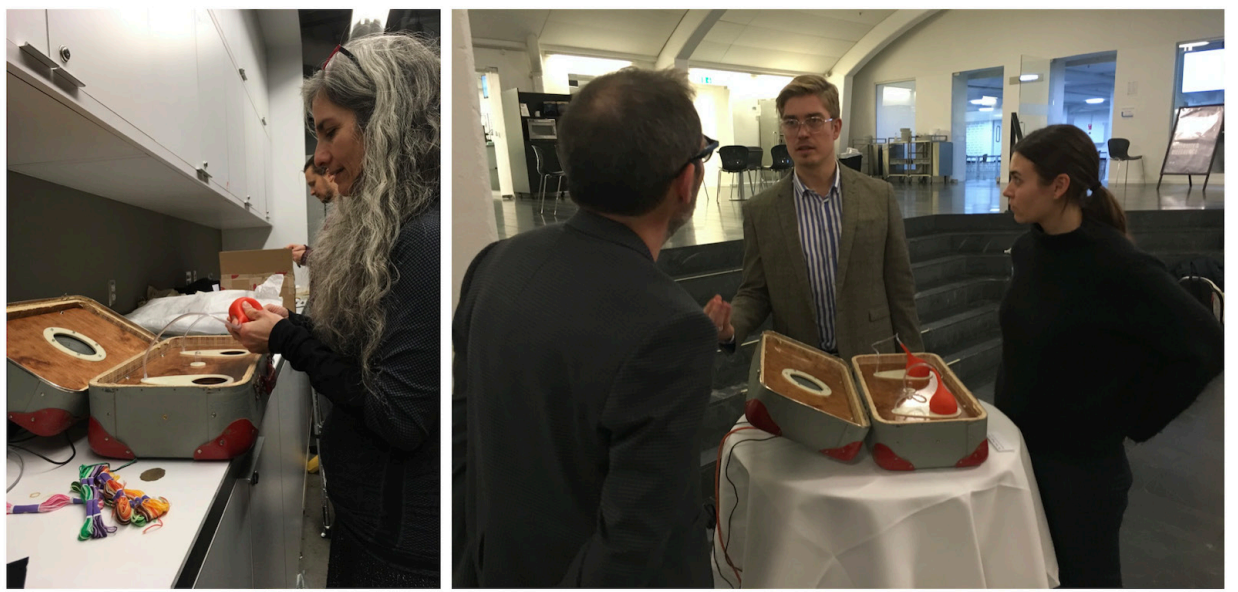

Figure 6. Two quite different venues; the Voice Pump at Distributing the Insensible workshop in Montréal (December 2016), and at the Diversity, Inequality and Transformations in the Digital Age, event at the Copenhagen Business School (November 2018). Photos by Jonas Fritsch.

based on vocal qualities rather than to make the content decipherable since the voices were Danish and thus speaking in another language than most of the workshop participants. We received many responses about the form of interaction and people, generally, found it interesting. We discovered, however, that people did not spend much time exploring the installation and, even though there are two pumps, most people would only try out the installation individually and not in pairs. Based on the presentation of the project and feedback from people, we became further aware of the potentially exclusionary nature of only recording and presenting voices from non-native Danish speakers. Indeed, when the voices were distorted, it was suggested that there might be an even more interesting approach in using the processing of the voices to increasingly blur elements of gender and nationality. This would make the interplay between difference and sameness more apparent; all the voices could potentially be the same but would bifurcate into different actualizations based on the interaction.

In November 2018, the Voice Pump was exhibited at a one-day event on Diversity, Inequality and Transformations in the Digital Age at the Copenhagen Business School. Here, the organizers had specifically contacted us 
based on an online description of the installation because they believed the project resonated with the main concepts of the event. In a way, the Voice Pump functioned as a 'conversation piece,' framing discussions around diversity, inequality, and digital transformation throughs its interactive setup. We framed this as an event activating "differential attunement with others"; as Brian Massumi (2015) suggests, "we're all in on the event together, but we're in it together differently. We each come with a different set of tendencies, habits, and action potentials" (115). The Voice Pump, we argue, can potentially be seen as a technological exploration that makes this differential felt through interaction.

Though encounters with and through the Voice Pump have resulted in design changes as well as changes in creative and critical dialogue and more playful interactions, also non-encounters have deeply influenced our continued work with the installation. The most important of these is the lack of direct encounter with the refugees originating the entire project in 2015. An obvious critique of the installation could be that it did not change anything for the refugee group nor really change the attitudes of people towards the refugees. The quick answer to these questions is no and most likely not. As discussed above, there were many reasons for not engaging directly with refugees in Denmark. Bringing Donna Haraway into consideration, there is a very real sense of not properly having "stayed with the trouble" (2015), but rather of having moved sideways. For instance, it is quite plausible that a non-technological focus on fundraising, activist protest, and community engagement through the Trampoline House would have made a much bigger impact. However, there is no doubt that the refugee crisis was a key event for initiating and problematizing the design process. And through the prism of this initial questioning situation, other themes have emerged: the infrastructural setup and the experimental, air-based interaction; the use of voices as a means of affective engagement to draw people into the interaction and as material for design; the ways in which the installation as a hands-on prototype would contribute to the thinking and articulation of affect theoretical concepts and concerns across venues and so forth. But when it comes to fulfilling the initial idea of engaging with refugees in Denmark, the Voice Pump falls short-but in a way that opens new problematic fields. 
On a number of levels, working with the installation has been a way of problematizing and "crafting other tales" (Stengers 2009, 17), and continuously asking "what if?" and producing new questions to be pursued under the heading of affective interaction design. The focus on building longterm relationships to ground design work with a societal reach is currently being explored in a design collaboration with an urban garden initiative. Byhaven (the City Garden) at Sundholm, uses gardening as a form of social rehabilitation for socially marginalized people, e.g., homeless people and those with different forms of abuse and mental health problems. The garden's physical location is just next to the IT University, and over the past two years we have initiated multiple workshops, mutual visits, and design intervention, building commitment with the stakeholders and users of the place. This has provided a strong foundation for doing projects that actually contribute to the different challenges and needs articulated by Byhaven users. Among other things, we are exploring the use of interactive sound for community storytelling and attunement to the qualities of plants and trees in an urban environment.

The Voice Pump was never a user-driven design project, not driven by actual needs of the group it wished to mobilize. Although the Byhaven collaboration could be seen as moving in the user-driven direction, a different research direction that has emerged that concerns the need for affective interaction design, grounded in lasting relationships, and based on the perceived emotional needs of particular user groups. So far, this has led to collaborations with a company involved in designing mobile apps to improve the wellbeing and coping strategies of chronic disease patients with rheumatoid arthritis and psoriasis. Through different means of self-reporting and self-tracking, mobile apps allow people to input and visualize data on how they are feeling so they can use that to foreground the emotional dimension of coping with a chronic disease, both as a tool for self-reflection but also in clinical consultations. Even though this might be seen as a move from the more abstract explorations of Voice Pump to something very concrete, in affective interaction design these positions would be within a continuum and not dichotomies. Jumping from abstract to concrete and back has important consequences for broadening the scope of the design space and are mutually beneficial strategies for the continued explorations of the problematic fields arising across affect studies and interaction design. 


\section{AN AFFIRMATIVE ETHICS OF TECHNOLOGY AND ECOLOGICAL ALTER-POLITICS OF DESIGN}

In the introduction to this chapter, we boldly stated that we would attempt to problematize across affect studies and interaction design to propose, 1) an affirmative ethics of technology exploration in affect studies fueled by design experiments, and 2) sketch out an ecological alter-politics of interaction design based on affect theoretical insights. It is now time to revisit these propositions using the design and analysis of the Voice Pump as a prism - not to find definite answers, but to creatively problematize these statements.

The first proposition points towards the role of technologic experimentation and exploration within affect philosophy/studies, adding a creative and affirmative stance to the absolutely necessary critical interrogation of the ways in which digital and interactive technologies profoundly impact our current existential conditions. Building on Deleuze and, more recently, Rosi Braidottis' (2018/2019a) work within transversal post-human studies, this will tentatively be phrased as an 'affirmative ethics' of technology. In A Theoretical Framework for the Critical Posthumanities, Braidotti offers numerous examples of how to address the role technological media, actors, and advances play in our contemporary lives. Rather than attempting to critique at a distance, Braidotti's conceptual engagement foregrounds the necessity to explore both critically and creatively the way digital and interfacial foldings impact our present moment. This can be seen in continuation of Haraway's call to investigate technologies as "companion species" (2003/16), keeping in mind that the post- nonand more-than-human must also develop a take on the digital dimensions of such technologies. This is, however, not the same as saying that there is always a technological solution to a clearly demarcated problem; rather, following the work of Gilbert Simondon, it can be seen as technological experimentation towards new and richer ways of re-fielding experience (Simondon 2005; Brunner \& Fritsch 2011/2020) towards "technologies of emergent experience" (Massumi 2002, 192) rather than capitalist capture.

For design, it is important to emphasize that an affect-oriented perspective entails more than bringing affect to the front of attention; it literally changes all associated concepts and can contribute to sketching out an ecological alter-politics of design (Fritsch \& Fritsch 2016). In the article entitled The Half-life of Disaster in The Guardian (April 15, 2011) in the 
wake of the Fukushima meltdown in 2011, Brian Massumi suggests that in a time characterized by shock and catastrophe as the norm rather than the exception, it is necessary to envision an ecological alter-politics which, he emphasizes, must also be an alter-politics of affect (Massumi 2011). Within critical anthropology, Ghassan Hage (2012/2015) has shown new ways of opening up a space for radical otherness within and among us inspired by the anthropological ethos of "we can be other than we are" $(2012,295)$. Radical political imaginaries according to Hage, contain elements of what he calls anti-politics and alter-politics. Whereas anti-politics describes a kind of oppositional politics that seeks to challenge, resist, or defeat forces dominating the current state of affairs, alter-politics aims at creating spheres for alternatives to flourish. According to Hage, sociology has been particularly attentive to anti-politics, while the critical anthropological tradition has been more aligned with alter-political dimensions of new political imaginaries, attuning more to alternatives that emerge from a space distinct from opposition. An affective, ecological alter-politics of design would take affect as a troubling starting point for rethinking existing ethical, political and cultural dimensions in design towards new radical imaginaries. Affective interaction design can be seen as an attempt to cultivate a research agenda that directly explores this, but it should be noted that an affect-driven approach could play a vital role in rethinking range of practices and commitments across a much wider spectrum of current HCI and interaction design research.

Whereas the "alter" in design would call for fully exploring the extent and reach of an affective politics in, for, and through design, the "alter" might also be posed as a relevant conceptual framing of the affirmative ethics of technology in affect studies; there is a need to cultivate, simultaneously, the "anti" and the "alter" to make an actual impact on the practical applications and necessary developments in design. Following Stengers, in our present catastrophic times, there is "no standing place outside of the alternative: refusing to opt and opting against it are equivalent when we are confronted with the question of lives worth living in the ruins" (Stengers 2019,19). This will be the starting point for continuously problematizing affective interaction design towards future ethopoietic adventures of ideas, combining a mutually evolving ethos of experimentation with an emergent research agenda for affective interaction design. 


\section{NOTES}

1. In my PhD dissertation (2009) and an article (2018), I have explicated in more detail this specific trajectory.

2. Interestingly, this is very much in line with Stenger's call to allow yourself to be touched and take action based on this, as presented above.

3. The technical refinement and physical shaping of the interactional devices is documented in detail in Fritsch \& Jacobsen 2017.

4. Workshops/academic events: Affects, Interfaces, Events workshop at ITU (March 2017), Distributing the Insensible (Montréal, December 2016), Affect-o-meeting (Weimar, August 2017), Minor Movements/Recommoning Infrastructures (ITU Copenhagen, September 2019). Presentations + Exhibitions: Summit-oplæg (Sound in Interaction Design, September 2017), CBS-oplæg (Diversity, Inequality and Transformations in the Digital Age, November 2018), Kulturnat/Culture Night (Medical Museion, different sound content, October 2017), Kulturnat/Culture Night 2018 (October 2018, collection of voices), Kulturnat/Culture Night 2019.

5. https://airlab.itu.dk/

\section{REFERENCES}

Aboulafia, A. \& Bannon, L. J. (2004). Understanding Affect in Design: An Outline Conceptual Framework. Theoretical Issues in Ergonomics Science 5 (2), pp. 4-15.

Bennet, J. (2001). The Enchantment of Modern Life: Attachments, Crossings, and Ethics. Princeton: Princeton University Press.

Boehner, K., DePaula, R., Dourish, P. \& Sengers, P. (2005). Affect: From Information to Interaction. Proceedings of the 4 th Decennial Conference on Critical Computing, New York: ACM.

Braidotti, R. (2019). A Theoretical Framework for the Critical Posthumanities. Theory, Culture \& Society [online] 36 (6), pp. 31-61. Available at: https://doi.org/10.1177/0263276418771486 [Accessed 23 June 2020].

Braidotti, R. (2019a). Posthuman Knowledge. London \& New York: Polity Press.

Brunner, C. \& Fritsch, J. (2011). Interactive Technologies as Fields of Transduction. Fibreculture 124, pp.118-145. 
Brunner, C \& Fritsch, J. (2020). Shifting Immediations: Fields of Experience across Media Art and Design. In: ISEA, eds., Proceedings of the 26th International Symposium of Electronic Arts, ISEA 2020: Why Sentience? Montreal: Printemps Numerique, pp. 91-97.

Bødker, S., Kyng, M., Ehn, P, Kammersgaard, J. \& Sundblad, Y. (1987). A Utopian Experience: On Design of Powerful Computer-based Tools for Skilled Graphic Workers. In: G. Bjerknes, P. Ehn \& M. Kyng, eds., Computers and Democracy: A Scandinavian Challenge. Århus: Gower Publishing, pp. 251-278.

Clough, P. T. ed., (2007). The Affective Turn: Theorizing the Social. Durham: Duke University Press.

Deleuze, G. (1970/1988). Spinoza: Practical Philosophy. San Francisco: City Lights Books.

Dunne, A. (1999). Hertzian Tales: Electronic Products, Aesthetic Experience and Critical Design. London: Royal College of Art Research Publications. Frayling, C. (1993). Research in Art and Design. Royal College of Art Research Papers, 1(1), pp. 1-5.

Fritsch, J. (2009). Understanding Affective Engagement as a Resource in Interaction Design. In: Proceedings of Engaging Artifacts. Nordic Design Research Conference.

Fritsch, J. (2011). Affective Experience as a Theoretical Foundation for Interaction Design. PhD dissertation, Deptartment of Information and Media Studies, Aarhus University.

Fritsch, J. \& Iversen, O. S. (2014). Designing for Experience: Scaffolding the Emergence of a Design Ecology. In: B. T., Knudsen, D. R. Christensen, \& P. Blenker, eds., Enterprising Initiatives in the Experience Economy: Transforming Social Worlds. Durham: Duke University Press, pp. 226-244.

Fritsch, J. \& Fritsch, E. (2016). Anarchival Proposals in Design Anthropology. In: Andrew Murphie, ed., The Go-To How To Book of Anarchiving, Montréal: Senselab.

Fritsch, J. \& Jacobsen, M. (2017). The Voice Pump: An Affectively Engaging Interface for Changing Attachments. DIS'17, Edinburgh.

Fritsch, J. (2018): Affective Interaction Design at the End of the World. In: Proceedings of the Design Research Society (DRS) Conference, Limerick, Ireland, pp. 896-908. Available at: https:/https://www. theguardian.com/commentisfree/2011/apr/15/half-life-of-disaster/ doi.org/10.21606/dma.2017.580 [Accessed 23 June 2020]. 
Gregg, M. \& Seigworth, G. J. (2010). The Affect Theory Reader. Durham: Duke University Press.

Guattari, F. (2000/1989). The Three Ecologies. London: Continuum.

Hage, G. (2012). Critical Anthropological Thought and the Radical Political Imaginary Today. Critique of Anthropology 32 (3), pp. 285-308.

Hage, G. (2015). Alter-politics: Critical Anthropology and the Radical Imagination. Melbourne: Melbourne University Press.

Haraway, D. (2003). The Companion Species Manifesto. Dogs, People and Significant Otherness. Chicago: University of Chicago Book Press.

Haraway, D. (2016). Staying with the Trouble: Making Kin in the Chthulucene. Durham: Duke University Press.

Höök K. (2008). Affective Loop Experiences: What Are They? In: H. Oinas-Kukkonen, P. Hasle, M. Harjumaa, K. Segerståhl \& P. Øhrstrøm, eds., PERSUASIVE 2008: Persuasive Technology, Lecture Notes in Computer Science, Vol. 5033 [online]. Berlin: Springer. Available at: https:// d10.10.21606/dma.2017.58021606/dma.2017.580oi.org/10.1007/9783-540-68504-3_1 [Accessed 23 June 2020].

James, W. (1912/2008). Essays in Radical Empiricism, New York: Cosimo Inc. Lottridge, D., Chignell, M. \& Jovicic, A. (2011). Affective Interaction: Understanding, Evaluating, and Designing for Human Emotion. Reviews of Human Factors and Ergonomics (7)1, 2011, pp. 197-237.

Massumi, B. (2002). Parables for the Virtual: Movement, Affect, Sensation. Durham: Duke University Press.

Massumi, B. (2009). On Microperception and Micropolitics. Inflexions: A Journal for Research-creation 3, pp.1-20.

Massumi, B. (2011). The Half-life of Disaster. [online] The Guardian. Available at: https://www.theguardian.com/commentisfree/20110.https:// core.ac.uk/reader/18663933721606/dma.2017.5801/apr/15/half-lifeof-disaster Accessed June 232020 [Accessed 23 June 2020].

Massumi, B. (2011). Affective Attunement in a Field of Catastrophe: A Conversation between Brian Massumi, Erin Manning, Jonas Fritsch, and Bodil Marie Stavning Thomsen. [online] Peripeti. Available at: http://www.peripeti.dk/2012/06/06/affective-attunement-in-afield-of-catastrophe/ [Accessed 23 June 2020].

Massumi, B. (2015). The Power at the End of the Economy. Durham: Duke University Press. 
Munteanu, C., Molyneaux, H., Moncur, W., Romero, M., O’Donnel, S. \& Vines, J. (2015). Situational Ethics: Re-thinking Approaches to Formal Ethics Requirements for Human-Computer Interaction. In: Proceedings of CHI'15. New York: ACM, pp. 105-114.

McCarthy, J. \& Wright, P. (2004). Technology as Experience. Cambridge: MIT Press.

Norman, Donald A. (2004). Emotional Design. New York: Basic Books. Picard, R.W. (1997). Affective Computing. Cambridge: MIT Press.

Sengers, P., Liesendahl, R., Magar, W., Seibert, C., Müller, B., Joachims, T., Geng, W., Mårtensson, P. \& Höök, K. (2002). The Enigmatics of Affect. In: Proceedings of DIS2002, London, pp. 87-98.

Simondon, Gilbert. (1964/2005). L'individuation à la lumière des notions de formes et d'information. Paris: Millon.

Smith, H. \& Dean, R. T. (2009). Practice-led Research, Research-led Practice in the Creative Arts. Edinburgh: Edinburgh University Press.

Souriau, E. (2015). On the Mode of Existence of the Work To-Be-Done: The Different Modes of Existence. Minneapolis: Univocal Publishing. Spinoza, B. (1678/1957). Ethics. New York: Citadel Press.

Stengers, I. (2019). Putting Problematization to the Test of Our Present. Theory, Culture \& Society [online] 38 (2), pp. 71-92. Available at: https:// doi.org/10.1177/0263276419848061 [Accessed 23 June 2020].

Stengers, I. (2009/2013). In Catastrophic Times: Resisting the Coming Barbarism. London: Open Humanities Press.

Stern, D. (1985). The Interpersonal World of the Infant. New York: Basic Books.

Whitehead, A. N., (1929/1979). Process and Reality: An Essay in Cosmology. Columbus: The Columbus Free Press.

Zimmerman, J., Forlizzi, J. \& Evenson, S. (2007). Research Through Design as a Method for Interaction Design Research in HCI. In: Proceedings of the SIGCHI Conference on Human Factors in Computing Systems. New York: ACM, pp. 493-502. 